\title{
ASR Expansions in Concrete under Triaxial Confinement
}

\author{
Joaquín Liaudata,*, Ignacio Carola ${ }^{\mathrm{a}}$, Carlos M. López ${ }^{\mathrm{a}}$, Victor E. Saouma ${ }^{\mathrm{b}}$ \\ ${ }^{a}$ Department of Environmental and Civil Engineering, Technical University of Catalonia, \\ 08034 Barcelona, Spain \\ ${ }^{b}$ Department of Civil, Environmental and Architectural Engineering, University of \\ Colorado, Boulder CO 80309, USA
}

\begin{abstract}
It is well known that the Alkali-Silica Reaction (ASR) expansion in concrete is influenced by the stress state of the material. However, the extent and nature of this influence is not completely understood due to the scarcity of experimental investigation under triaxial stress states. This paper presents experimental ASR expansion curves obtained from cubical concrete specimens subjected to three different triaxial stress states, by means of a new testing machine especially designed for this purpose. The results seem to confirm that the volumetric ASR expansion rate is reduced as the applied volumetric compressive stress is increased. Additionally, there seems to be an increase of the expansion rate in the less compressed direction in detriment of the expansion rates in the most compressed ones.
\end{abstract}

Keywords: alkali-silica reaction, multiaxial stress, durability

\footnotetext{
${ }^{*}$ Corresponding author

Email addresses: joaquin.liaudat@upc.edu (Joaquín Liaudat), ignacio.carol@upc.edu (Ignacio Carol)
} 


\section{Introduction}

Since the early investigations on ASR in concrete, it was noticed that the stress state has an influence on the magnitude and distribution of ASRinduced cracking and expansions [1]. Stresses may be due to external loads applied to the structure or the reaction to constrained expansion due to internal (rebars) or external restraints.

In the last two decades, a number of experimental studies on the effect of mechanical restraints on the development of ASR expansions have been proposed. A first group of experimental studies to deal with this problem consisted in impeding the longitudinal expansion of mortar or concrete bars via very stiff loading frames, e.g. $[2,3,4,5]$. This setup makes it possible to measure what is called "expansive" or "swelling pressure", i.e. the stress

developed in the specimen in the restrained direction. Kagimoto et al. [6], introduced a variation to this scheme by performing tests with loading frames of different stiffnesses. Refer to Fig. 1a for a schematic representation of these kind of tests. The results obtained in this setup are difficult to interpret since the evolution of the swelling pressure will not only depend on the ASR mechanisms, but also on the rheological behavior of concrete due to the development of internal pressures.

A second group of studies consisted in applying a constant axial load on cylindrical specimens (Fig. 1b), usually via creep frames, e.g. $[7,8$, 9]. To isolate ASR expansions, creep deformations due to the applied load are deducted from the overall expansion curve obtained. Since, for obvious reasons, it is not possible to directly measure creep on reactive concretes, creep strains had to be assessed on concretes with similar characteristic but 


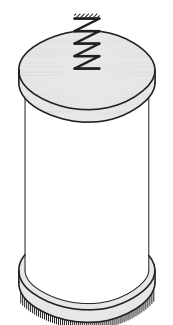

(a)

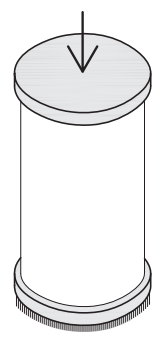

(b)

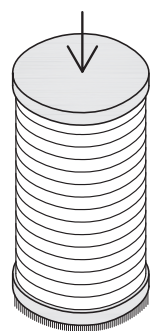

(c)
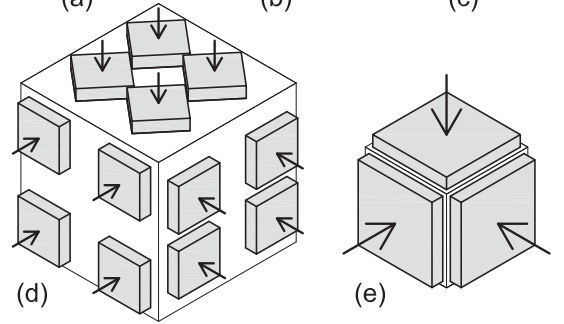

Figure 1: Schematic representation of ASR expansion tests under different mechanical restraints.

with non-reactive aggregates or by means of analytical expressions from the literature. A similar approach is followed to deduct shrinkage strains when they are significant.

In the work of Multon and Toutlemonde [8], some specimens were also tested with passive radial restraint, in order to induce triaxial stress in the material. The radial restraint to expansion was added by means of steel rings 3- or 5-mm-thick, which were not connected to each other so that they would not exert any longitudinal restriction (Fig. 1c). This setup has the drawback that the radial stresses are not constant but linearly dependent on the expansion in this direction, making the interpretation of the results troublesome.

Finally, in a recent work, Gautam and Panesar [10] have proposed an ingenious test setup for measuring ASR expansions in concrete under constant triaxial stress states. For these tests, cubic specimens of $254 \times 254 \times 254$ 
mm were loaded by means of post-tensioning bolts (Fig. 1d). The bolts were stressed close to the yield limit of steel, in such a way that any additional elongation of the bolt induced by ASR expansion in the concrete will not induce any significant increase of the reaction exerted by the bolts on the specimen. The main drawback of this setup is that the stress distribution in the specimens is highly nonuniform, since the stresses concentrate under the bolt anchors. Therefore, the interpretation of the results requires estimation of the real distribution of stresses in the specimen via numerical modeling.

In this paper, a new testing machine for performing ASR expansion tests with cubic concrete specimens under constant triaxial stress is presented. The equipment has the advantage that the stresses are applied by means of six loading plates that cover most of the surface of the specimen, creating, in that way, a quasi-uniform stress state inside the material (Fig. 1e). The machine has been used to obtain ASR expansion curves for three different stress states which are also presented and discussed in this paper. Complementarily, a number of mechanical tests were performed to characterize the concrete tested, both before and after the ASR expansion tests.

\section{AAR Triaxial Machine}

With the aim of measuring ASR expansions in concrete under true triaxial confinement, i.e. under different constant stress along each of the main directions, an ad hoc testing machine, called "Alkali-Aggregate Reaction Triaxial Machine" (AARTM), was originally designed and constructed by the fourth author at the U. of Colorado - Boulder. Later, in 2010, it was transferred to UPC (Barcelona) where a number of modifications were introduced 
to the original set-up.

The AARTM consists of a triaxial load frame which can deliver 0 to 9 MPa confining stress on each axis of a $150 \times 150 \times 150 \mathrm{~mm}$ cubical specimen. Specimen deformation is measured using three displacement sensors on each of the three axes. The apparatus is designed to be capable of raising and maintaining the specimen temperature at a pre-set value between $30-70{ }^{\circ} \mathrm{C}$, and the faces of the loading plates in contact with the specimens are crossed by grooves for a solution to circulate in order to keep the specimen wet and supply reactants (alkalis). A LabVIEW-based computer control and data acquisition system maintains the desired confining stress and specimen temperature while logging all relevant data points.

\subsection{Loading frame}

A three-piece steel assembly is used to provide reaction forces for the three hydraulic actuators. The frame is constructed of W12 $\times 24$ I-beams and designed to deflect less than $0.25 \mathrm{~mm}$ under the full $220 \mathrm{kN}$ confinement load. Each section of the frame is bolted together at the vertical axis to form a monolithic structure. Refer to Fig. 2 for a general view of the load frame assembly.

\subsection{Triaxial confinement and measurement systems}

The AARTM is equipped with three $220 \mathrm{kN}$ hydraulic actuators and six $138.3 \times 138.3 \mathrm{~mm}$ stainless steel loading plates used to apply the confining

stress to the test specimen. Actuators are connected to the three "active" loading plates by means of cylindrical steel rods. Three additional steel rods of similar length connect the "passive" plates to the loading frame. Each 


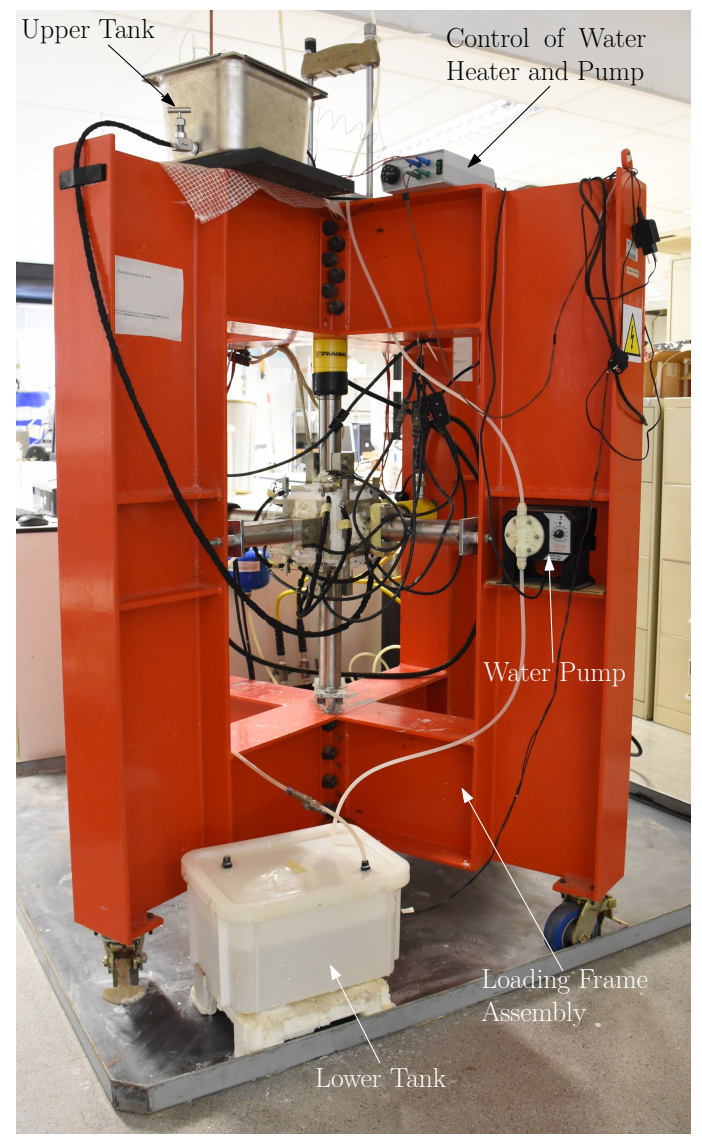

Figure 2: General view of the AARTM.

rod was drilled to accept a $32 \mathrm{~mm}$ pin used to transfer the confining load to the loading plates. Active rods were machined to thread into the hydraulic actuators, while the passive rods were threaded to accept a large nut. The nut provides an adjustment mechanism for aligning the non-active loading plates. Refer to Fig. 3 for a view of the load application system.

The nominal applied stress is calculated as the ratio between the applied load and the nominal surface area of a specimen $(150 \times 150 \mathrm{~mm})$. It must be noted that the surface area of the plates is slightly smaller than that of 


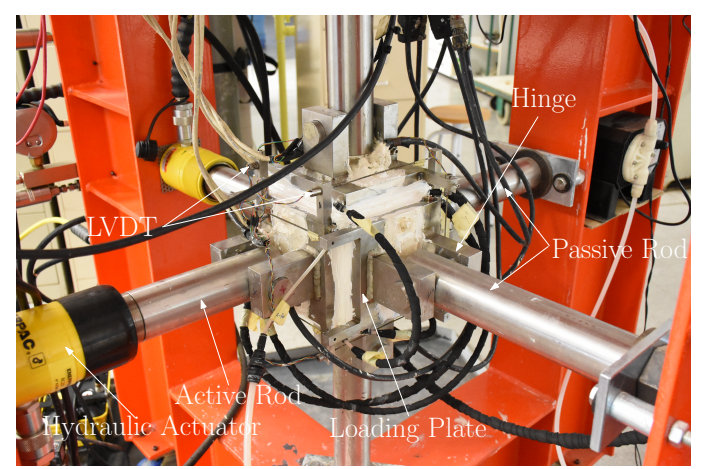

Figure 3: Detail view of the AARTM.

the face of the specimens and, therefore, the stresses within the specimen are not completely uniform. However, numerical simulations of a specimen subjected to the same load in each direction indicate that $91 \%$ of the volume of the specimen has stresses within $\pm 20 \%$ of the nominal ones.

Each of the three active loading plates connected to a hydraulic actuator is equipped with three Linearly Variable Differential Transformers (LVDTs), from Macro Sensors (model CD-375, range $\pm 2.54 \mathrm{~mm}$, linearity $\pm 0.5 \%$ ). Each LVDT senses the distance to the opposite plate by means of a threaded extension rod which is attached at the opposite plate end. Refer to Fig. 4 for the relative position of the LVDTs on the active loading plates. Strain in a given direction is then calculated as the ratio between the average relative displacements measured with the i- and j-LVDTs (see Fig. 4, left), and the initial specimen dimension in that direction (approx. $150 \mathrm{~mm}$ ). The k-LVDT is used for monitoring the relative rotation between opposite plates.

\subsection{Temperature control system}

A closed-loop temperature control system is employed on the AARTM to accelerate the AAR. Each stainless steel loading plate is equipped with 

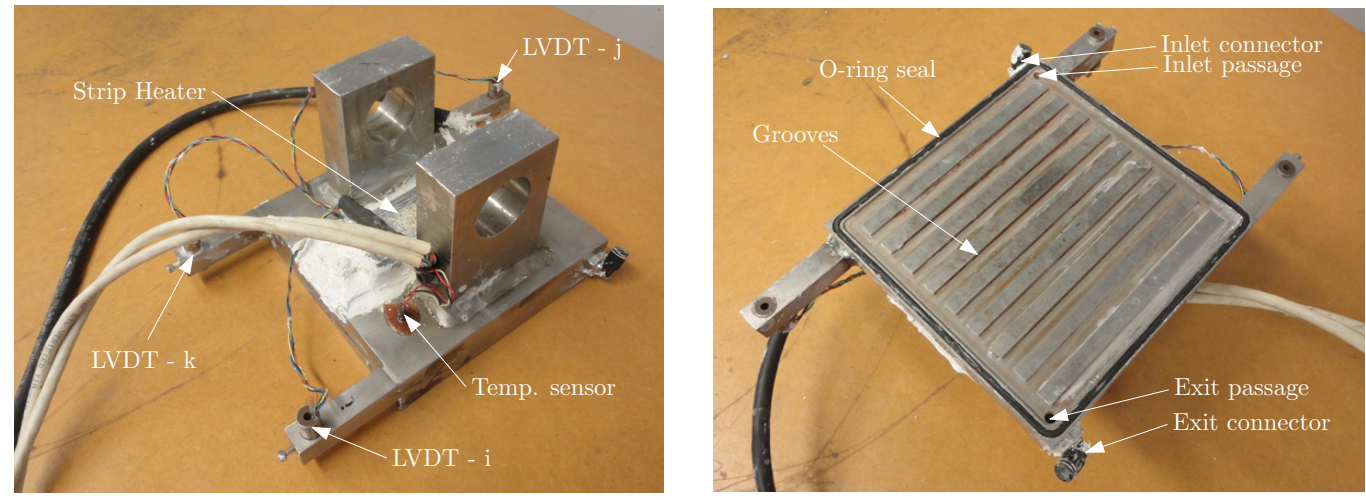

Figure 4: Detail views of an active loading plate of the AARTM.

a 150 Watt flush-mounted heating element (Fig. 3 and Fig. 4). The three active loading plates are equipped with precision temperature sensors (Fig. 4, left). Averaged temperature feedback from the loading plates is used for the closed-loop control. This system has proven to be stable and effective, reliably holding the specimen temperature constant within $\pm 1{ }^{\circ} \mathrm{C}$.

\subsection{Hydraulic load systems}

Three independent high pressure hydraulic loading systems, one for each axis direction, are employed to provide specimen confining stress via the stainless steel loading plates. These systems utilize pneumatic energy delivered via the laboratory compressed air distribution system to drive three hydraulic pumps. The air flow to the hydraulic pumps is controlled by the computer using direct acting electric solenoid valves. Varying the duration and interval in which the solenoid valves are open allows for proportional control of the pressure rise in the system. Each hydraulic circuit includes a hydraulic manifold where a pressure transducer, an analog pressure gauge and an adjustable pressure relief valve are installed. This pressure relief valve 
is set to a pressure slightly higher than the desired confining pressure and supplements the computer controlled hydraulic pump to provide tighter load regulation.

\subsection{Liquid circulation system}

As already mentioned, the face of the loading plates in contact with the specimen are crossed by grooves to allow the circulation of alkaline solution. Liquid leakage is prevented by means of Viton ${ }^{\text {TM }}$ O-rings in between the plates and the specimen. Refer to Fig. 4 for detail views of a loading plate. The sealing offered by the O-ring is not completely effective and needs to be complemented by the application of silicon sealant covering the specimenplate contours. The plates are connected to each other in a series circuit by means of polyamide $4 \times 2.7 \mathrm{~mm}$ hoses thermally insulated with self-adhesive tape of EPDM rubber foam. The alkaline solution circulates by gravity through the loading plates series circuit, from a stainless steel tank of $12 \mathrm{~L}$, located at the top of the loading frame, to a polyethylene tank of $20 \mathrm{~L}$ located at floor level (Fig. 2). The liquid flow is regulated manually by means of a stainless steel needle valve. Finally, a diaphragm pump commanded by a float switch in the upper tank, recirculates the liquid from the lower tank to the upper one. In order to prevent that the circulating liquid cools down the specimen, the upper tank is equipped with a $400 \mathrm{~W}$ electric cartridge heater commanded by a mechanical thermostat which keeps the liquid temperature close to the test temperature. 


\section{Experimental procedures}

\subsection{Concrete specimens}

Two different kinds of concrete were investigated. The first one, called "control concrete", was made only with non-reactive (crushed limestone) aggregates. The second one, called "reactive concrete", in contrast, was made using the same mixture but replacing the coarser fraction of aggregates with crushed colorless soda-lime glass as reactive aggregate. Control specimens were tested in the same conditions as the reactive specimens in order to assess creep and/or shrinkage deformations. The cement used was CEM I 42,5 N-SR 5 [11]. Both mixtures had a cement content of $420 \mathrm{~kg} / \mathrm{m}^{3}$ and a water/cement weight ratio of 0.45 . The alkali level of the concrete was raised to $5.25 \mathrm{~kg} / \mathrm{m}^{3} \mathrm{Na}_{2} \mathrm{O}_{\text {eq }}$ by adding $\mathrm{NaOH}$ to the mixing water. The non-reactive aggregate was well graded and passed a $12.70 \mathrm{~mm}$ sieve. For the reactive concrete, the coarser $64 \%$ of the non-reactive aggregate volume (particles between 2.50 and $12.70 \mathrm{~mm}$ ) was replaced by crushed soda-lime glass particles.

The specimens were cast at four different times. Control and reactive specimens cast on the same date constitute a "casting set", which is indicated for each tested specimen in Table 1. After casting, the specimens remained in molds for $24 \mathrm{~h}$ at room temperature and with the exposed surface covered with a plastic film in order to prevent moisture loss. Once demolded, specimens were put in $1 \mathrm{~m} \mathrm{NaOH}$ solution ( $1 \mathrm{~mol}$ of $\mathrm{NaOH}$ per $\mathrm{kg}$ of water) at room temperature $\left(21 \pm 2{ }^{\circ} \mathrm{C}\right)$ for at least three months. Before performing the expansion tests, the pouring face of each specimen was polished to remove excessive roughness. 
The curing solution, which was the same to be used for the following expansion tests, was chosen to have a total alkali concentration similar to that of the specimen pore solution, preventing in that way the reduction of the pore solution alkalinity due to alkali leaching towards the curing bath. The minimum extent of the curing period has been adopted based on previous tests (not published) which indicated that for shorter curing periods the expansion rate measured in the testing conditions described below is dependent on the age of the specimen.

\subsection{Free expansion test setup}

To assess the effect of the applied stress state on the ASR expansion rate, it is essential to perform additional free expansion measurements. These tests cannot be carried out with the AARTM since a minimum pressure is needed in each direction to ensure full contact of the loading plates with the specimen, in order to guarantee the sealing effect of the O-rings. Therefore, a different procedure described below was applied to perform a number of free expansion tests with specimens of identical characteristics to those used in the AARTM, and under the same exposure conditions (1 m NaOH solution at $\left.60{ }^{\circ} \mathrm{C}\right)$.

One week before starting the free expansion test, each specimen was removed from the alkaline curing bath and let air dry for $24 \mathrm{~h}$. Then, stainlesssteel datum discs were glued with epoxy resin to the specimen surface in the configuration indicated in Fig. 5. In all cases, the Z-direction was matched with the specimen casting direction. Each pair of datum discs allowed measuring the length change at the surface of the specimen in one main direction 
Table 1: List of tested specimens. Note: Id. = Identifier.

\begin{tabular}{|c|c|c|c|c|}
\hline Type & Id. & $\begin{array}{c}\text { Casting } \\
\text { set \# }\end{array}$ & $\begin{array}{c}\text { Curing } \\
\text { period } \\
\text { (weeks) }\end{array}$ & $\begin{array}{c}\text { Test } \\
\text { duration } \\
\text { (weeks) }\end{array}$ \\
\hline \multicolumn{5}{|c|}{ Load case $0-0-0$} \\
\hline \multirow[t]{4}{*}{ Reactive } & TM01 & 1 & 39 & 30 \\
\hline & TM10 & 2 & 14 & 36 \\
\hline & TM12 & 2 & 14 & 36 \\
\hline & TM13 & 2 & 14 & 36 \\
\hline \multirow[t]{3}{*}{ Control } & TM05 & 2 & 14 & 36 \\
\hline & TM06 & 2 & 14 & 36 \\
\hline & TM07 & 2 & 14 & 36 \\
\hline \multicolumn{5}{|c|}{ Load case $1-1-1$} \\
\hline \multirow[t]{2}{*}{ Reactive } & TM02 & 1 & 42 & 3 \\
\hline & TM21 & 3 & 39 & 5 \\
\hline \multirow[t]{2}{*}{ Control } & TM03 & 1 & 39 & 2 \\
\hline & TM19 & 3 & 35 & 3 \\
\hline \multicolumn{5}{|c|}{ Load case 9-9-1 } \\
\hline \multirow[t]{2}{*}{ Reactive } & TM11 & 2 & 44 & 3 \\
\hline & TM20 & 3 & 49 & 3 \\
\hline \multirow[t]{2}{*}{ Control } & TM08 & 2 & 34 & 3 \\
\hline & TM15 & 3 & 53 & 3 \\
\hline \multicolumn{5}{|c|}{ Load case 9-9-9 } \\
\hline \multirow[t]{2}{*}{ Reactive } & TM14 & 2 & 56 & 5 \\
\hline & TM22 & 3 & 67 & 3 \\
\hline \multirow[t]{2}{*}{ Control } & TM09 & 2 & 68 & 4 \\
\hline & TM16 & 3 & 63 & 3 \\
\hline \multicolumn{5}{|c|}{ Mechanical tests } \\
\hline \multirow[t]{3}{*}{ Reactive } & TM24 & 3 & 47 & none \\
\hline & TM30 & 4 & 15 & none \\
\hline & TM31 & 4 & 15 & none \\
\hline \multirow[t]{3}{*}{ Control } & TM18 & 3 & 47 & none \\
\hline & TM25 & 4 & 15 & none \\
\hline & TM26 & 4 & 15 & none \\
\hline
\end{tabular}


by means of a $100 \mathrm{~mm}$ DEMEC strain gage (Fig. 5). In part of the specimens, only one measurement in each direction (X1, Y1, Z1) was performed. After $24 \mathrm{~h}$, once the epoxy resin was cured, each specimen was placed in a $19 \mathrm{~L}$ airtight plastic container filled with $1 \mathrm{~m} \mathrm{NaOH}$ solution and kept at room temperature for another 5 days for rewetting. Afterwards, the containers with the specimens were introduced in an oven at $60{ }^{\circ} \mathrm{C}$. After $24 \mathrm{~h}$, the containers were removed from the oven in order to perform the first reading (zero-reading) in each pair of datum discs. Then, the containers with the specimens were returned to the oven and kept there at $60{ }^{\circ} \mathrm{C}$ until the next reading. The average temperature in the oven during the test was $59.95{ }^{\circ} \mathrm{C}$ with a standard deviation of $0.33{ }^{\circ} \mathrm{C}$. Measurements were made for total test duration of 30 weeks. For clarification, a schematic timeline of the testing procedure is given in Table 2 .

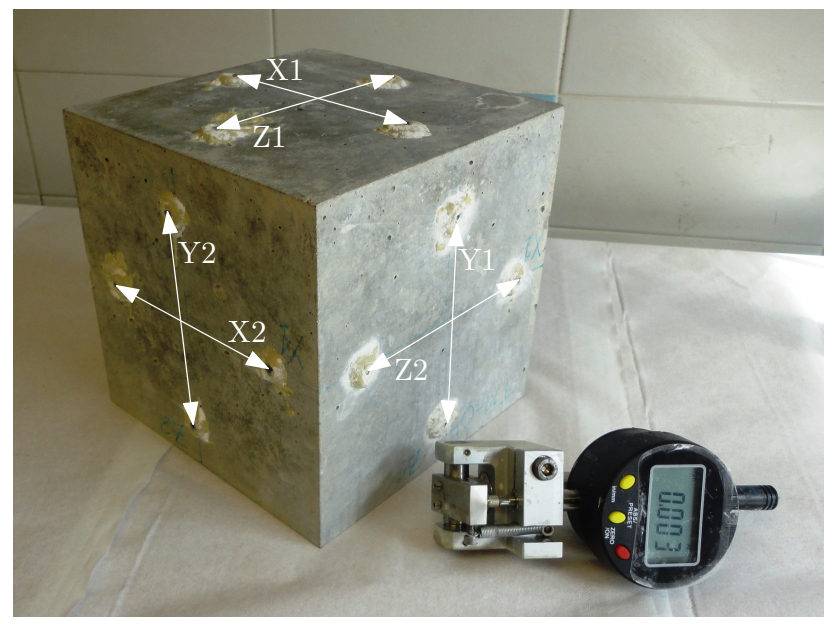

Figure 5: Specimen with datum discs and DEMEC strain gage used for strain measurement in free expansion tests. Z-direction was matched with the casting direction. 
Table 2: Schematic timeline of the free expansion tests. " $\mathrm{x}$ " denotes the age (in days) of the specimen when first removed from the alkaline bath.

\begin{tabular}{|c|c|}
\hline day 0 & - Concrete casting \\
\hline day 1 & - Unmolding \\
\hline$\ldots$ & $\begin{array}{l}\text { Curing in alkaline solution at room temperature } \\
\text { (between } 14 \text { and } 39 \text { weeks) }\end{array}$ \\
\hline day $x$ & - Removal of the specimen from the alkaline bath \\
\hline day $x+1$ & - Gluing of the datum discs \\
\hline day $x+2$ & - Returning specimen to the alkaline bath \\
\hline$\ldots$ & $\begin{array}{l}\text { Curing in alkaline solution at room temperature } \\
\text { ( } 5 \text { days })\end{array}$ \\
\hline day $x+7$ & - Heating up to $60{ }^{\circ} \mathrm{C}$ \\
\hline day $x+8$ & - Zero-reading \\
\hline$\ldots$ & Free ASR expansion (30 weeks) \\
\hline day $x+217$ & - End of test \\
\hline
\end{tabular}

\subsection{Confined expansion test setup}

The steps followed to perform a confined expansion test using the AARTM machine are schematically summarized in Table 3. First, the specimen was removed from the alkaline bath and let dry exposed to air for $24 \mathrm{~h}$. Then, a thin layer of silicone sealant was applied at the rims of each face of the specimen (20 mm inwards) and was let cure for $48 \mathrm{~h}$. This silicone layer improves the sealing function of the loading plates O-rings by providing them a smooth settlement surface. Afterwards, the specimen was placed in between of the loading plates of the AARTM and isotropically confined with a small pressure (0.30 MPa, approx.). Immediately, a thick layer of silicone sealant was applied covering the specimen-plate contours and was let cure for $72 \mathrm{~h}$, while keeping the confining pressure. Once the silicone was cured, the 
LVDTs cores and the hoses for liquid circulation were put in position. The $1 \mathrm{~m} \mathrm{NaOH}$ solution was allowed to circulate for $48 \mathrm{~h}$ at room temperature to re-saturate the specimen. In order to guarantee full contact between the specimen and the plates, previously to heating, the pressure in each direction was raised to $5 \mathrm{MPa}$ and then lowered again to $0.30 \mathrm{MPa}$, while maintaining the other two at $1 \mathrm{MPa}$. Next, the pressure was set again to isotropic $0.30 \mathrm{MPa}$ and the heating systems of the plates and alkaline solution tank were turned on. The target temperature of $60{ }^{\circ} \mathrm{C}$ was usually reached within an hour, moment in which the specimen was loaded to the desired stress state and the data acquisition started. These stress state and temperature were kept constant for at least 21 days. After that, in some cases, the load state was changed and the test continued for some additional time. The average temperatures during the test periods were slightly below the nominal, with values ranging between 59.88 to $59.98^{\circ} \mathrm{C}$, and with standard deviation always below $0.45{ }^{\circ} \mathrm{C}$. The average applied stresses during the test periods were within $5 \%$ of the nominal values, with standard deviations under $3 \%$. The total volume of circulating alkaline solution was over $25 \mathrm{~L}$ and the flow rate over $2 \mathrm{~L} / \mathrm{h}$.

\subsection{Mechanical test setups}

In order to assess the mechanical properties of the control and reactive concretes, a number of uniaxial compression tests (UCTs) and wedge splitting tests (WSTs) were performed. The WST procedure is described in detail in Ref. [12].

For the UCTs, the original cubic specimens of $150 \times 150 \times 150 \mathrm{~mm}$ were cut 
Table 3: Schematic timeline of the confined expansion tests. "x" denotes the age (in days) of the specimen when removed from the alkaline bath.

\begin{tabular}{|c|c|}
\hline day 0 & - Concrete casting \\
\hline day 1 & - Unmolding \\
\hline$\ldots$ & $\begin{array}{l}\text { Curing in alkaline solution at room temperature } \\
\text { (between } 34 \text { and } 68 \text { weeks) }\end{array}$ \\
\hline day $\mathrm{x}$ & $\begin{array}{l}\text { - Removal of the specimen from the alkaline bath } \\
\text { - Application of the silicone sealant layer at the } \\
\text { rim of each face of the specimen. }\end{array}$ \\
\hline day $x+2$ & $\begin{array}{l}\text { - Placing of the specimen in the AARTM } \\
\text { - Sealing of the contours of plate-specimen contacts }\end{array}$ \\
\hline day $x+4$ & - Beginning of the circulation of the alkaline solution \\
\hline day $x+7$ & $\begin{array}{l}\text { - Loading/unloading to } 5 \mathrm{MPa} \text { in each direction } \\
\text { - Heating up to } 60{ }^{\circ} \mathrm{C} \\
\text { - Application of the desired loading state } \\
\text { - Starting of data acquisition }\end{array}$ \\
\hline$\cdots$ & Confined ASR expansion (21 days) \\
\hline day $x+28$ & - End of test \\
\hline
\end{tabular}

with a diamond saw into four prismatic specimens of approximately $75 \times 75 \times$ $150 \mathrm{~mm}$. The prismatic specimens were cut in such a way that two of them were aligned with the casting direction and the other two were normal to it. To one specimen of each pair, two LVDTs (RDP GT2500, range $\pm 2.5 \mathrm{~mm}$, linearity error $< \pm 0.1 \%$ F.S.) were attached in the loading direction for measuring the material strain. The UCTs were performed with a controlled displacement rate of $0.25 \mathrm{~mm} / \mathrm{min}$. On the specimens with attached LVDTs, two load/unload cycles up to $1 / 4$ of the estimated compression strength were performed before the final loading until failure. The other two specimens were directly loaded until failure. The compression strength $\left(f_{c}\right)$ of the original cubical specimen is obtained as the average of the peak compressive stress of 
the four prismatic specimens. The initial tangent modulus $(E)$ is obtained as the average of the values obtained from the two prismatic specimen with attached LVDTs.

For the WSTs, the original cubic specimens were cut into two prismatic specimens of approximately $75 \times 150 \times 150 \mathrm{~mm}$. Then the grove and the notch were cut in such a way that the fracture path of one specimen was aligned with the casting direction, and in the other specimen was normal to it. The crack opening displacement (COD) was measured along the axis of the horizontal splitting force with two LVDTs (RDP GT2500, range $\pm 2.5 \mathrm{~mm}$, linearity error $< \pm 0.1 \%$ F.S.), one on each side of the specimen. The applied vertical load was measured with a $25 \mathrm{kN}$ load cell (UtilCell 610, linearity error $< \pm 0.25 \%$ F.S.). The COD rate was $0.125 \mathrm{~mm} / \mathrm{min}$. The specific

fracture energy of the original cubical specimen in mode $\mathrm{I}\left(G_{I}^{f}\right)$ is obtained as the average of the values obtained from the two prismatic specimens tested. Additionally, the tensile strength $\left(f_{t}\right)$ is estimated via numerical modeling according with the procedure described in Ref. [13].

\section{Results and discussion}

\subsection{Free expansion tests}

Three control specimens and four reactive specimens were tested in freeexpansion conditions. Refer to Table 1 for a list of the tested specimens with their respective curing and testing times. The strain measured for each specimen is presented in Fig. 6 as the average of the strain measured in each of the three directions of the specimen. The dashed lines indicate the envelope of the measured strain curves. 


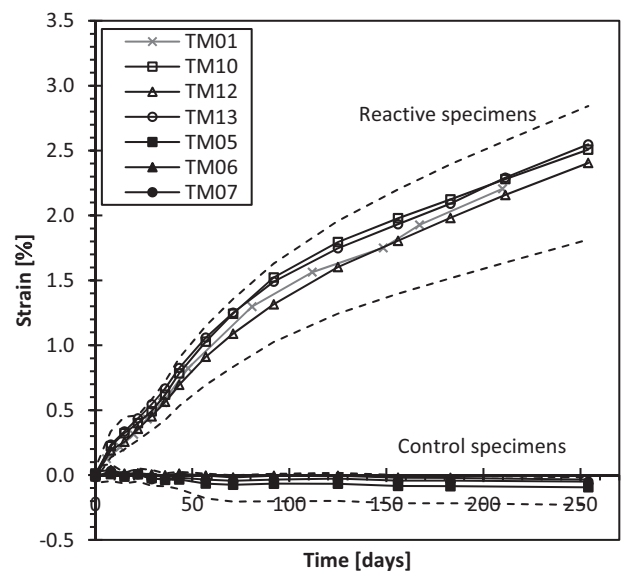

Figure 6: Averaged axial strain curves in free-expansion conditions of both reactive and control specimens. Dashed lines indicate the envelope of all the measured strain curves in the three directions.

As it can be seen in the figure, the control specimens developed a slight contraction of around $0.05 \%$ over the first 75 days and then seemed to stabilize. Reactive specimens exhibited a roughly constant expansion rate for strains below $1 \%$. Beyond that value, the expansion rate decreased until reaching an approximately constant value of about one fourth of the initial rate. Note that specimen TM01, which was 39 weeks-old when tested, showed a very similar behavior to that of the remaining reactive specimens of only 14 weeks. This seems to indicate that, at least within 14 to 39 weeks, the extent of the curing period does not affect the subsequent development of the ASR expansions. However, a systematic study would be needed to confirm this particular aspect. This issue is of interest since the specimens tested with the AARTM were of different ages, as it is indicated in Table 1.

\subsection{Confined expansion results}

Three nominal load cases were studied with the AARTM: 
- "Case 1-1-1", $\sigma_{x}=\sigma_{y}=\sigma_{z}=-1 \mathrm{MPa}$

- "Case 9-9-9", $\sigma_{x}=\sigma_{y}=\sigma_{z}=-9 \mathrm{MPa}$

- "Case 9-9-1", $\sigma_{x}=\sigma_{y}=-9 \mathrm{MPa}, \sigma_{z}=-1 \mathrm{MPa}$

In all cases the casting direction of the specimens was matched with the Zdirection of the AARTM. Per each load case, two control and two reactive specimens were tested. The list of the tested specimens with their respective curing and testing times is given in Table 1.

The reason for the control specimens is because concrete subject to sustained load will inevitably show creep (and possibly cracking) deformations, and therefore the strains measured for reactive specimens under loading will be the combined effect of both actions. Additionally, one can expect that the principle of superposition will not be strictly satisfied, i.e. the effect of simultaneous loading and ASR will not be equal to the sum of ASR strains of unloaded specimens plus mechanical deformations of similar non-reactive specimens. In this context, the approach followed is to accept the following conventional definitions:

- Basic creep: time-dependent deformations measured on control (nonreactive) specimens under load.

- ASR strain: difference between total deformations measured on reactive specimens under load and basic creep.

With this convention, possible interaction effects of the simultaneous action of loading and ASR, are folded into the "ASR strain", which will be also 
dependent on stress as shown in the following sections. Note that this approach has already been used in the literature $[7,8,9]$ and it is conceptually similar for instance to the standardized procedure for the separation of creep and shrinkage strains.

\subsubsection{Strain curves of control specimens}

The axial strain curves obtained from control specimens are given in Fig. 7a to c. All the specimens experienced a monotonous contraction with decreasing rate throughout the test. Test on specimen TM03 (Fig. 7a) was ended prematurely due to a leak of alkaline solution.

In these plots we may distinguish two different kinds of scatter. On one hand, there are differences between curves of different axes of the same specimen that should, in principle, be equal since they were subject to the same load. See for instance the curves of specimen TM19 (Fig. 7a), which was subject to the 1-1-1 loading and, nevertheless, the strain curves exhibit non-negligible differences. This scatter seems to be random and intrinsic to the creep phenomenon itself and/or to the testing procedure.

On the other hand, there are differences within the curves of the two specimens tested with the same load case. For instance, specimens from the casting set \#3 (TM19 and TM15) experienced higher contractions than specimens from casting sets \#1 (TM03) and \#2 (TM08). This seems to indicate that concrete form casting set \#3 had different creep properties than the ones from casting sets $\# 1$ and \#2. Based on this assumption, it was decided that the control specimen used for creep deduction of a given reactive specimen had to be from the same casting set. For instance, creep of reactive specimen TM02 was deducted considering the strain curves of 

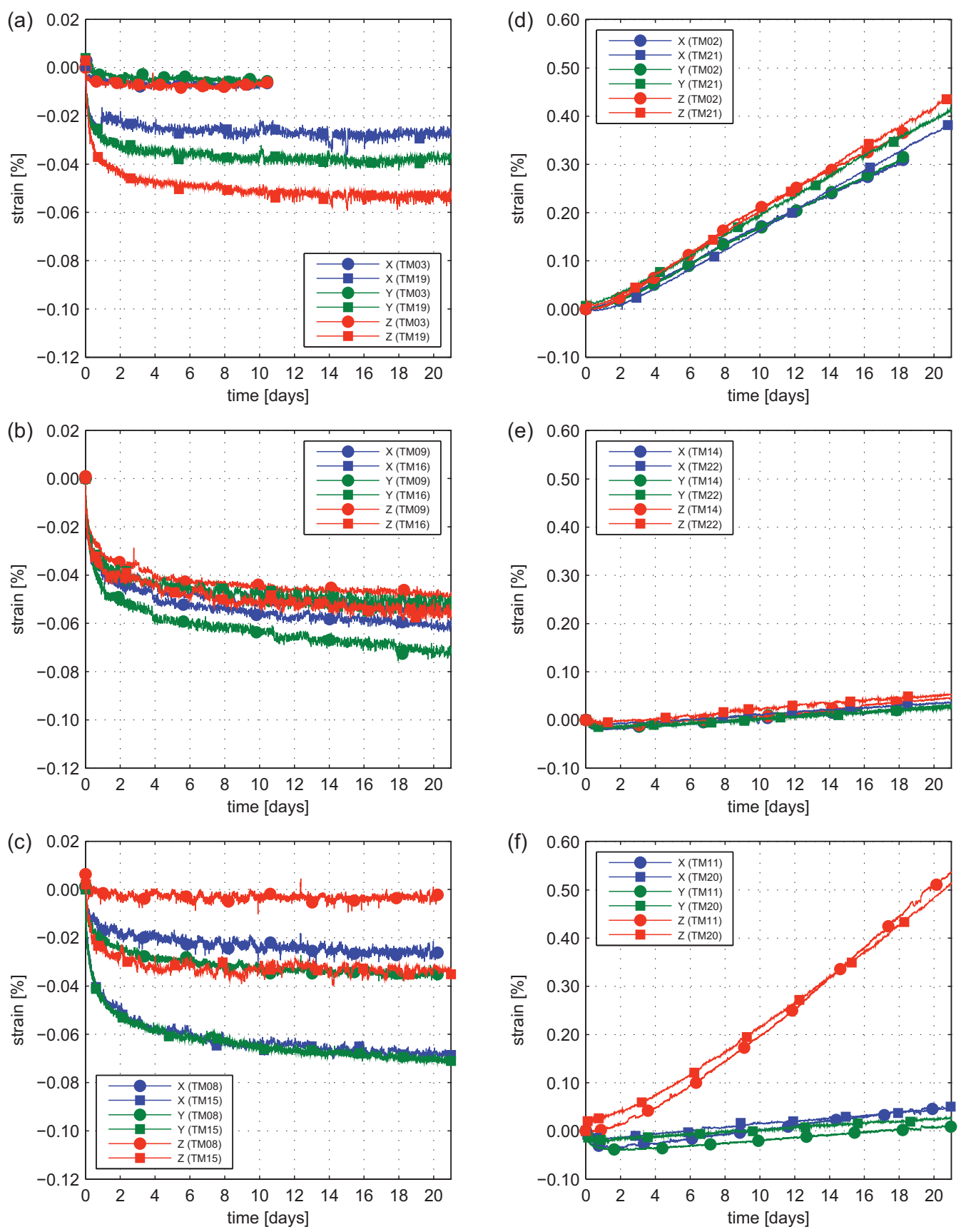

Figure 7: Axial strain curves of control specimens under (a) 1-1-1, (b) 9-9-9, and (c) 9-9-1 load cases; axial strain curves, after deducting creep, of reactive specimens under (d) 1-1-1, (e) 9-9-9, and (f) 9-9-1 load cases. 
control specimen TM03, because both belonged to the same casting set (see Table 1).

\subsubsection{Strain curves of reactive specimens}

The axial strain curves of reactive specimens, after deducting creep, are plotted in Figs. 7d to 7f. As already explained, the creep deduction consisted in directly subtracting, for each load case, the strains measured in the control specimens from those measured in the reactive ones. To do so, firstly the control specimen strain curves were fitted with a proposed logarithmic function. Then, the fitted creep function was used to estimate the creep strains to be deducted from the measured total strains in the reactive specimens. The creep function adopted and the procedure followed to fit the function parameters are described in detail in the Appendix A. It must be noted that within the term creep we are denoting all the time dependent strains measured on control specimens, including concrete creep, but probably also the deformation of the silicone layers and the O-rings in between the specimen faces and the machine loading plates.

As shown in Figs. 7d to 7f, the differences between curves of specimens tested with the same load case are within the expected scatter for ASR expansion tests. In all cases, the maximum expansion rates needed between 2 and 4 days to be reached. For applied stress of $9 \mathrm{MPa}$, the strain curves in the corresponding direction, exhibited a slight contraction during the first day that is eventually overcome by expansions (Figs. 7e and 7f). This seems to indicate that the creep strains measured on control specimens were smaller than those occurring in the corresponding reactive ones. However, this difference cannot be attributed to ASR since it is observed at the very beginning 


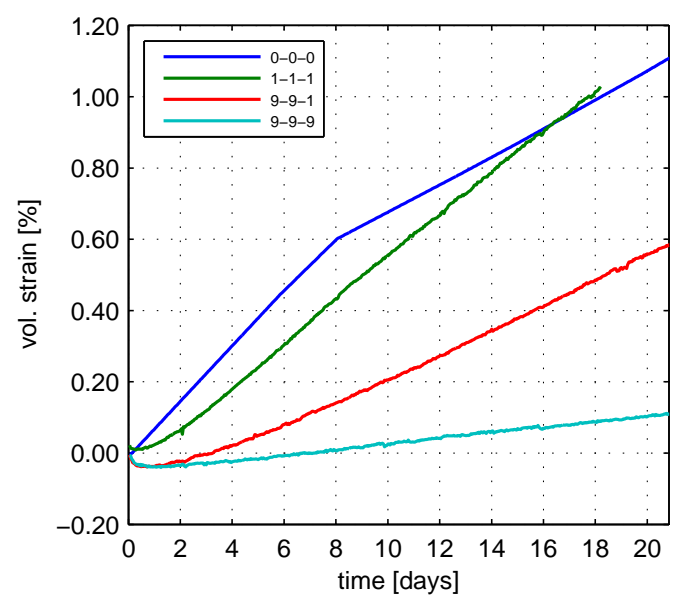

Figure 8: Comparison of average volumetric strain curves, after deducting creep, of reactive specimens under different triaxial confinement.

of the tests when the effect of ASR may be regarded as insignificant. Then, it seems more likely to be the result of differences in the mechanical/creep parameters of control and reactive concrete, as it is discussed in Section 4.4.

In Fig. 8, the average of the volumetric strain curves obtained for each load case, after deducting creep, are plotted together, including the free expansion case (0-0-0). The bi-linear shape of the free expansion curve is because the specimen deformations were measured only three times in the first 21 days.

For a quantitative analysis of the effect of stresses, axial and volumetric expansion rates obtained from the curves plotted in Figs. $7 \mathrm{~d}$ to $7 \mathrm{e}$ are summarized in Table 4 . The expansion rates were obtained by fitting the expansion curve points $\left(t, \varepsilon_{i}^{a s r}\right)$, with a straight line between $t=4$ and $t=21$ days for the specimens tested in the AARTM, and between $t=0$ and $t=21$ days for the free expansion tests. The volumetric expansion rate was obtained as the sum of the three axial expansion rates. In Fig. 9 (primary load states), 


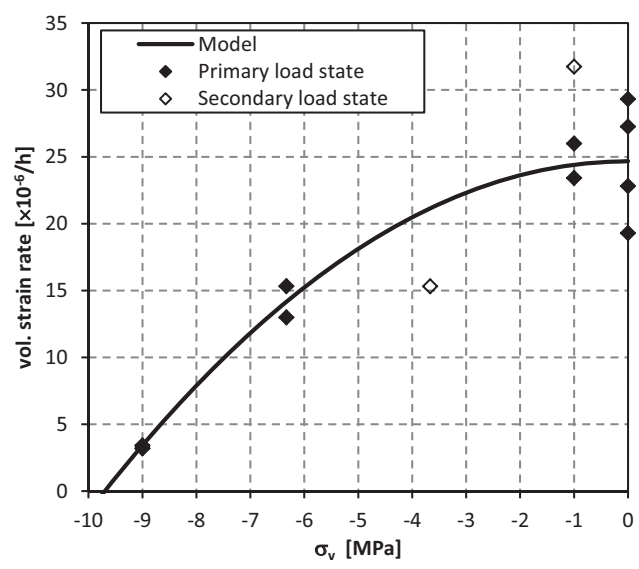

Figure 9: Volumetric strain rate of tested reactive specimen versus applied volumetric stress. Creep effects have only been deducted from the specimens under primary load states.

volumetric expansion rates are plotted against the applied volumetric stress.

The volumetric expansion rate was practically the same for load cases 0-0-0 and 1-1-1. However, for load cases 9-9-1 and 9-9-9 the volumetric expansions rate was reduced significantly as the mean compression stress was increased.

Under isotropic stress states (0-0-0, 1-1-1 and 9-9-9) the axial expansion rate in the casting direction (Z-direction) was greater than that of the other two directions of the same specimen, therefore possibly revealing a constitutive anisotropy of the specimens. This phenomenon has been observed by many researchers, e.g. in Refs. [7, 8]. The rate of ASR expansion in Zdirection measured for the load case 9-9-1 was greater than the one measured for load case 1-1-1, while in the other two directions the expansion rates were similar to those obtained for load case 9-9-9. Somehow, the confinement applied on X- and Y-directions increased the expansion rate in the less stressed 
Table 4: Axial and volumetric ASR expansion rates expressed in $\left[10^{-6} \mathrm{~h}^{-1}\right]$. Creep has been deducted for primary load cases but not for secondary load cases (marked with "**"). Values calculated with the proposed model are given in between brackets.

\begin{tabular}{|c|c|c|c|c|c|c|c|}
\hline Id & $\dot{\varepsilon}_{x}^{a s r}$ & $\dot{\varepsilon}_{y}^{a s r}$ & $\dot{\varepsilon}_{z}^{a s r}$ & $\dot{\varepsilon}_{v}^{a s r}$ & $\begin{array}{l}\dot{\varepsilon}_{x}^{a s r} \\
\dot{\varepsilon}_{v}^{a s r}\end{array}$ & $\begin{array}{l}\dot{\varepsilon}_{y}^{a s r} \\
\dot{\varepsilon}_{v}^{a s r}\end{array}$ & $\begin{array}{l}\dot{\varepsilon}_{z}^{a s r} \\
\dot{\varepsilon}_{v}^{a s t}\end{array}$ \\
\hline \multicolumn{8}{|c|}{ Load Case 0-0-0 } \\
\hline TM01 & 5.48 & 7.21 & 6.61 & 19.29 & 0.28 & 0.37 & 0.34 \\
\hline TM10 & 9.17 & 6.99 & 11.10 & 27.26 & 0.34 & 0.26 & 0.41 \\
\hline TM12 & 7.42 & 5.88 & 9.52 & 22.82 & 0.33 & 0.26 & 0.42 \\
\hline TM13 & 9.45 & 9.94 & 9.93 & 29.32 & 0.32 & 0.34 & 0.34 \\
\hline Average & 7.88 & 7.50 & 9.29 & 24.67 & 0.32 & 0.31 & 0.38 \\
\hline Model & (8.22) & (8.22) & (8.22) & $(24.67)$ & $(0.33)$ & $(0.33)$ & $(0.33)$ \\
\hline \multicolumn{8}{|c|}{ Load Case 1-1-1 } \\
\hline TM02 & 7.27 & 7.54 & 8.61 & 23.41 & 0.31 & 0.32 & 0.37 \\
\hline TM21 & 8.47 & 8.43 & 9.09 & 26.00 & 0.33 & 0.32 & 0.35 \\
\hline Average & 7.87 & 7.99 & 8.85 & 24.71 & 0.32 & 0.32 & 0.36 \\
\hline Model & $(8.14)$ & $(8.14)$ & $(8.14)$ & $(24 \cdot 41)$ & $(0.33)$ & $(0.33)$ & $(0.33)$ \\
\hline \multicolumn{8}{|c|}{ Load Case 9-9-1 } \\
\hline TM11 & 1.88 & 1.16 & 12.29 & 15.33 & 0.12 & 0.08 & 0.80 \\
\hline TM20 & 1.27 & 0.93 & 10.80 & 13.00 & 0.10 & 0.07 & 0.83 \\
\hline Average & 1.58 & 1.04 & 11.55 & 14.17 & 0.11 & 0.07 & 0.82 \\
\hline Model & (1.13) & (1.13) & (11.89) & $(14.15)$ & $(0.08)$ & $(0.08)$ & $(0.84)$ \\
\hline \multicolumn{8}{|c|}{ Load Case 9-9-9 } \\
\hline TM14 & 1.04 & 1.06 & 1.32 & 3.41 & 0.30 & 0.31 & 0.39 \\
\hline TM22 & 1.00 & 0.95 & 1.26 & 3.20 & 0.31 & 0.30 & 0.39 \\
\hline Average & 1.02 & 1.00 & 1.29 & 3.31 & 0.31 & 0.30 & 0.39 \\
\hline Model & (1.14) & (1.14) & $(1.14)$ & $(3.43)$ & (0.33) & (0.33) & (0.33) \\
\hline \multicolumn{8}{|c|}{ Load Case $1-1-1$ after $9-9-9(*)$} \\
\hline TM14 & 10.70 & 9.94 & 11.10 & 31.74 & 0.34 & 0.31 & 0.35 \\
\hline Model & $(8.06)$ & $(8.06)$ & $(8.06)$ & $(24.41)$ & (0.33) & (0.33) & $(0.33)$ \\
\hline \multicolumn{8}{|c|}{ Load Case 1-9-1 after 1-1-1 (*) } \\
\hline TM21 & 7.72 & 0.42 & 7.18 & 15.32 & 0.50 & 0.03 & 0.47 \\
\hline Model & $(10.15)$ & $(0.85)$ & $(10.15)$ & (21.15) & $(0.48)$ & $(0.04)$ & $(0.48)$ \\
\hline
\end{tabular}




\section{Z-direction.}

Based on the same concepts as proposed in Saouma and Perroti [14], a new formula is proposed to predict the observed ASR volumetric expansion rate under compressive stresses $\left(\dot{\varepsilon}_{v}^{a s r}\right)$ :

$$
\dot{\varepsilon}_{v}^{a s r}=\Gamma_{c}\left(\sigma_{v}\right) \dot{\varepsilon}_{v, f r e e}^{a s r}
$$

where $\dot{\varepsilon}_{v, \text { free }}^{a s r}$ is the rate of volumetric ASR expansion without applied stresses, and $\Gamma_{c}$ is a dimensionless factor that accounts for the reduction of $\dot{\varepsilon}_{v}^{a s r}$ under compressive stresses, which is assumed to be a function of the volumetric stress $\sigma_{v}$ as follows

$$
\Gamma_{c}=\left\{\begin{array}{clrl}
1 & \text { if } & \sigma_{v} \geq 0 \\
1-\left(\sigma_{v} / \bar{\sigma}_{v}\right)^{2} & \text { if } & 0> & \sigma_{v} \geq \bar{\sigma}_{v} \\
0 & \text { if } & & \sigma_{v}<\bar{\sigma}_{v}
\end{array}\right.
$$

where $\bar{\sigma}_{v}$ is a parameter that stands for the volumetric stress under which ASR expansion would be totally suppressed. This value is taken as $-9.7 \mathrm{MPa}$ (in contrast with Saouma and Perotti expression in which $\bar{\sigma}_{v}$ was made equal to the characteristic compression strength of concrete). The volumetric stress is defined as $\sigma_{v}=\left(\sigma_{1}+\sigma_{2}+\sigma_{3}\right) / 3$ where $\left(\sigma_{1}, \sigma_{2}, \sigma_{3}\right)$ are the principal stresses.

Then, the reduced volumetric rate is distributed in the three principal directions by means of the formula given in Saouma and Perotti [14] as follows:

$$
\dot{\varepsilon}_{i}^{a s r}=W_{i}\left(\sigma_{1}, \sigma_{2}, \sigma_{3}\right) \dot{\varepsilon}_{v}^{a s r}
$$

where $\dot{\varepsilon}_{i}^{a s r}$ is the ASR expansion rate in the principal axis $i$, and $W_{i}$ is a 
weight factor for the principal axis $i$, which is a function of the three principal stresses and is calculated following the procedure proposed by Saouma and Perotti [14]. For comparison, the ASR expansion rates values obtained using these formulae are informed in between brackets in Table 4. As can be seen, a fairly good agreement is obtained. It is remarkable that the weight factors proposed by Saouma and Perotti based on the experimental results of Multon and Toutlemonde [8] are in very good agreement with the ones resulting from our tests, despite the fact that the constitutive anisotropy of the specimens in the casting direction (Z-direction) is not reproduced.

It has to be recognized that the model represented by Eqs. 1-3 is a drastic simplification of a complex phenomenon involving cracking, creep and chemotransport processes at various levels of observation. Therefore, the curves and parameters values obtained have a phenomenological character and may change for different concretes, exposure conditions, etc. Nevertheless, it is remarkable that, as said before, this simple approach can fit data from at least two independent test series.

\subsection{Effect of changing the stress state}

In order to have some insight into the effect of changing the stress states on the ASR expansion rates, after the standard testing time (21 days) had been completed, the stress states of two specimens (TM14 and TM21) were changed and the tests continued for an additional period of approximately 12 days.

After the 21 days under 9-9-9 load case, the stresses on specimen TM14 were reduced to 1-1-1. As a result, the expansion rate increases significantly as can be appreciated in Fig. 10a. Since the counterpart control specimen 
was not subject to the same change of the stress state, the curves presented in Fig. 10a are the raw ones, i.e. without any creep deduction. The expansion rates were maximum immediately after the stress change, decreasing asymptotically to constant rate values in the following days. Interestingly, no instantaneous (elastic) expansions associated with the reduction of the compression stresses can be observed in the curves. The asymptotic expansion rates, presented in Table 4 and Fig. 9 (secondary load states), were obtained by fitting the expansion curve points $\left(t, \varepsilon_{i}\right)$ with a straight line between $t=25$ and $t=32$ days. These values are $30 \%$ greater than the ASR expansion rates obtained for load case 1-1-1 (Table 4). Note that the expansion rates obtained for the secondary load cases are not only attributable to ASR since strains due to other causes have not been deducted. In this case, the decompression of the specimen may have originated a differed elastic creep expansion which could explain, at least in part, the initial variation of the expansion rates. Other causes related with the ASR expansion mechanisms may also be considered. For instance, the greater initial expansion rate may be attributed to the swelling of ASR gel formed under the 9-9-9 stress state due to water absorption when the confining stresses reduce to 1-1-1. In any case, additional testing would be necessary to explain in more detail the observed behavior.

For specimen TM21, the stress state was changed after 22 days from 1-1-1 to 1-9-1. The resulting raw expansion curves are presented in Fig. 10b. In this case, in contrast with the previous one, instantaneous strains are clearly appreciated: a negative strain jump in the Y-direction and smaller positive strain jumps, attributable to Poisson's effect, in the X- and Z-directions. 

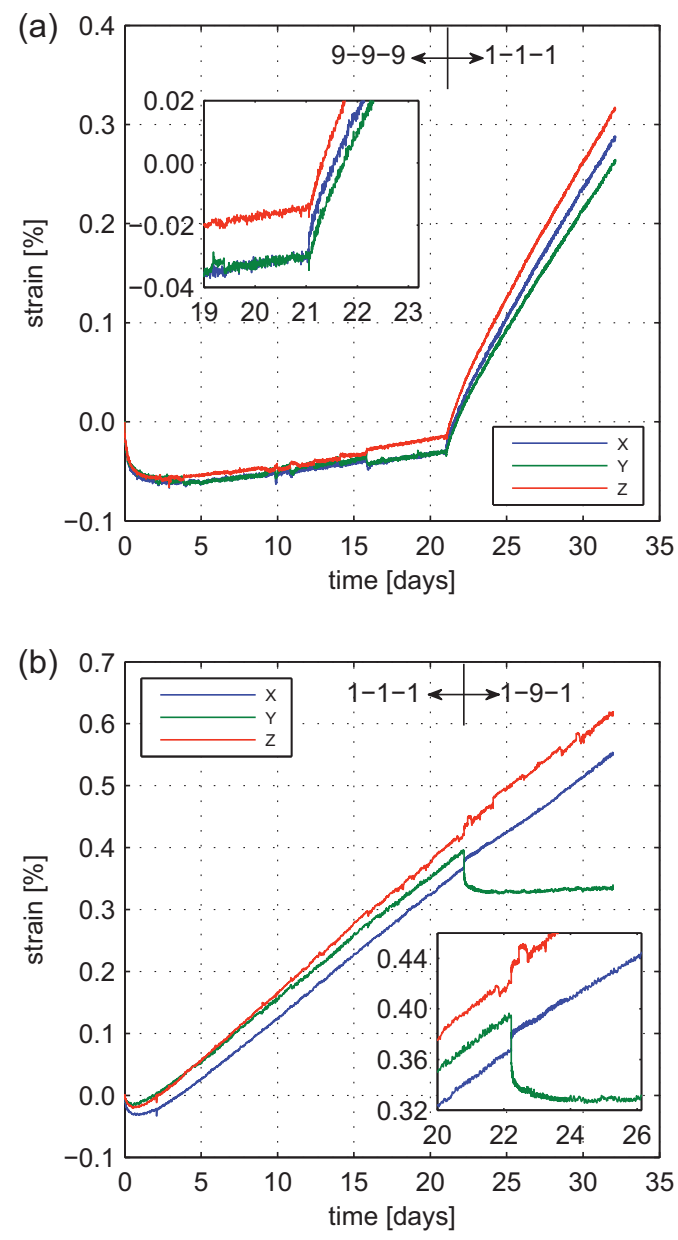

Figure 10: Axial strain curves (without deducting any creep effects) of: (a) reactive specimen TM14, first subjected to load case 9-9-9 for 21 days and then to load case 1-1-1 until the end of the test; (b) reactive specimen TM21, first subjected to load case 1-1-1 for 22 days and then to load case 1-9-1 until the end of the test. 
After that, the expansion in the Y-direction practically stops, while in the $\mathrm{X}$ - and Z-directions it continues but with a rate 10 to $20 \%$ smaller than for the previous 1-1-1 stress state. In the same way as for the previous specimen, the expansion rates for the 1-9-1 stress state has been estimated and reported in Table 4. Again, the lack of a counterpart control specimen with the same stress history makes it impossible to deduct creep and therefore obtain the net ASR expansion rates. However, one can estimate that the deduction of the creep strains in this case would result in a slight increase of the expansion rate in the Y-direction and an even smaller, if any, reduction in the X- and Z-direction rates, due to Poisson's effect on creep strains. Therefore, the increase of the Y-stress seems not only to have reduced the Y-direction expansion rate but also the expansions on the other two axes. Again, additional testing would be needed to confirm these observations.

Finally, the expressions proposed in Eqs. 1 to 3 were used to estimate the ASR expansion rates under the secondary load cases. The values obtained are reported in between brackets in Table 4. As it can be seen, the weight factors are in good agreement with the experimental ones. However, the volumetric expansion rates are not very well predicted.

\subsection{Mechanical test results}

The results obtained are summarized in Table 5. The initial elastic modulus $(E)$ and the compression strength $\left(f_{c}\right)$ were measured on control and reactive specimens subjected to four different histories of curing and ASR testing. The specific fracture energy in mode $\mathrm{I}\left(G_{I}^{f}\right)$ and the tensile strength $\left(f_{t}\right)$ were obtained only from control and reactive specimens which had been cured for 15 weeks but had not been subject to ASR testing. 
Table 5: Results of the performed mechanical tests: initial tangent modulus $(E)$, compression strength $\left(f_{c}\right)$, tensile strength $\left(f_{t}\right)$, and specific fracture energy in mode I $\left(G_{I}^{f}\right)$.

\begin{tabular}{lccccc}
\hline Type & Id. & $\begin{array}{c}\mathrm{E} \\
{[\mathrm{GPa}]}\end{array}$ & $\begin{array}{c}f_{c} \\
{[\mathrm{MPa}]}\end{array}$ & $\begin{array}{c}f_{t} \\
{[\mathrm{MPa}]}\end{array}$ & $\begin{array}{c}G_{I}^{f} \\
{\left[\mathrm{~J} / \mathrm{m}^{2}\right]}\end{array}$ \\
\hline Cured for 15 weeks \\
\hline Control & TM25 & 41.5 & 42.5 & - & - \\
Reactive & TM30 & 21.5 & 26.8 & - & - \\
Control & TM26 & - & - & 2.8 & 74.6 \\
Reactive & TM31 & - & - & 2.4 & 144.1 \\
Cured for 47 weeks & & & \\
Control & TM18 & 40.0 & 60.5 & - & - \\
Reactive & TM24 & 19.0 & 24.9 & - & - \\
Cured for 63-67 weeks and tested $9-9-9$ for 3 weeks \\
\hline Control & TM16 & 40.3 & 54.3 & - & - \\
Reactive & TM22 & 25.5 & 34.4 & - & - \\
Cured for 14 weeks and tested $0-0-0$ for 36 weeks \\
\hline Control & TM07 & 41.7 & 52.6 & - & - \\
Reactive & TM13 & 5.6 & 8.5 & - & - \\
\hline
\end{tabular}

Lets first consider the results from the specimens cured for 15 weeks and without ASR testing. The $E$ and $f_{c}$ measured for control concrete are significantly higher than those measured on reactive concrete. In contrast, the $G_{I}^{f}$ measured on reactive concrete is practically twice the one measured on control concrete, while the estimated $f_{t}$ values are similar. These differences can be attributed to the flaky shape and to the smoothness of the crushed glass particles. Since concrete creep in absolute terms is known to decrease with increasing elastic modulus, the creep strain experienced by control specimens during the confined expansion tests may have been lower than the ones experienced by reactive specimens. This may explain the initial contraction observed in the ASR expansion curves in the direction under -9 MPa stress 
(Fig. 7e and f), and indicate that the actual ASR expansion rates may have been slightly higher than those reported in Table 4 . An effort shall be made in future tests in order to obtain similar mechanical parameters in control and reactive concretes.

When considering the remaining results, it seems that curing and testing history only have an influence on the measured values of $f_{c}$ and $E$ on reactive concrete but not on control concrete. Comparison of results from specimens TM30 and TM24 (curing times of 15 and 47 weeks, respectively) suggests that ASR degradation occurring at curing conditions was not significant, even when some signals of occurring ASR (ASR gel spots, slight cracking) were detected on the specimen cured for 47 weeks. In contrast, $E$ and $f_{c}$ values from specimen TM13, which was previously tested in free expansion conditions for 36 weeks and experienced ASR expansions of about $2.5 \%$ (Fig. 6), showed important reductions in comparison with those measured on TM30. Finally, specimen TM22, which had a longer curing period and was tested for 3 weeks experiencing some ASR expansions (0.05\%, Fig.7e), not only did not degrade its mechanical parameters but actually improved them.

\section{Concluding remarks}

Accelerated ASR expansion tests performed on cubical concrete specimens under free and triaxially-confined expansion conditions have been presented. Two different concrete mixtures were tested under the same conditions, one reactive, with crushed soda-lime glass aggregate, and one nonreactive. 
For the triaxially-confined tests, an ad hoc testing machine for AAR confined expansion tests was designed and constructed. This machine has shown to be capable of accurately apply and maintain targeted true-triaxial compressive stress states and temperature on the tested specimen, while keeping it in contact with a highly alkaline solution.

The results seem to indicate that the volumetric ASR expansion rate is reduced as the applied volumetric compressive stress is increased. Addition-

ally, there seems to be an increase of the expansion rate in the less compressed direction in detriment of the expansion rates in the most compressed ones. These observations are in good agreement with the model previously proposed by the fourth author [14], although a correction is proposed for the dependency of total volumetric expansion with volumetric stress.

Future work is intended to use the presented testing methodology for studying concrete made with natural reactive aggregates.

\section{Acknowledgements}

This research is supported by grants BIA2016-76543-R from MEC (Madrid), which includes FEDER funds, and 2014SGR-1523 from AGAUR-Generalitat de Catalunya (Barcelona). Initial funding for the AARTM was provided by the Tokyo Electric Power Company to the fourth author. The first author thanks the scholarship FPI (BES-2010-030515) from MEC (Madrid).

\section{Appendix A. Creep deduction}

The simplest possible creep deduction procedure was based in three assumptions. The first one was that the measured strains of the reactive speci- 
mens $\mathbf{e}^{r e a}=\left[\begin{array}{lll}\varepsilon_{x}^{r e a} & \varepsilon_{y}^{r e a} & \varepsilon_{z}^{r e a}\end{array}\right]$ were the addition of two independent terms, on one hand the ASR expansion term $\left(\mathbf{e}^{a s r}\right)$ and on the other the "creep" strain term $\mathbf{e}^{c r}$, i.e.

$$
\mathbf{e}^{r e a}=\mathbf{e}^{a s r}+\mathbf{e}^{c r}
$$

The second assumption was that the creep strains in the reactive specimens were the same as those measured in the control specimens $\left(\mathbf{e}^{\text {con }}\right)$ under the same conditions, i.e.

$$
\mathbf{e}^{c r}=\mathbf{e}^{c o n}
$$

Finally, the third assumption was that the strains developed by the control specimens subject to a constant stress state can be properly approximated with a function $C_{i}(t)$ which is fitted independently for each axis of loading $i$,

$$
C_{i}(t)=\left\{\begin{array}{cc}
0 & \text { if } t \leq t_{i} \\
m_{i} \ln t+b_{i} & \text { if } t>t_{i}
\end{array}\right.
$$

where $t$ is the time elapsed since the moment when the specimen is loaded (beginning of the test), $t_{i}=\exp \left(-b_{i} / m_{i}\right), b_{i}$ and $m_{i}$ are fitting parameters. Best fitting values of $m_{i}$ and $b_{i}$ were obtained for each tested control specimen by applying the least squares method.

Under these three assumptions, the ASR expansion curves for a given stress state was readily obtained as:

$$
\mathbf{e}^{a s r}=\mathbf{e}^{r e a}-\mathbf{C}(t)
$$




\section{References}

[1] J.K. McGowan, H.E. Vivian, The Effect of Superincumbent Load on Mortar Bar Expansion. Australian J. of Appl. Science 6 (1955) 94-99.

[2] C.F. Ferraris, J.R. Clifton, E.J. Garboczi, F.L. Davis, Stress Due to Alkali-Silica Reaction in Mortars, in: K.L. Scrivener, J.F. Young (Eds.), Mechanisms of Chemical Degradation of Cement-based Systems, E. \& F.N. Spon, London, 1995, pp. 75-82.

[3] C.F. Ferraris, E.J. Garboczi, F.L. Davis, J.R. Clifton, The effect of stress relaxation, self-desiccation, and water absorption on the alkalisilica reaction in low water/cement ratio mortars. Cem. Concr. Res. 27 (1997) 1553-1560.

[4] M. Kawamura, K. Iwahori, ASR gel composition and expansive pressure in mortars under restraint, Cem. Concr. Compos. 26 (2004) 47-56.

[5] A. Binal, The determination of gel swelling pressure of reactive aggregates by ASGPM device and a new reactive-innocuous aggregate decision chart, Constr. Build. Mater. 22 (2008) 1-13.

[6] H. Kagimoto, Y. Yasuda, M. Kawamura, ASR expansion, expansive pressure and cracking in concrete prisms under various degrees of restraint, Cem. Concr. Res. 59 (2014) 1-15.

[7] C. Larive, Combined contribution of experiments and modelling to the understanding of alkali-aggregate reaction and its mechanical consequences (PhD thesis, in French), École Nationale des Ponts et Chaussées, 1998. 
[8] S. Multon, F. Toutlemonde, Effect of applied stresses on alkali-silica reaction-induced expansions, Cem. Concr. Res. 36 (2006) 912-920.

[9] C.F. Dunant, K.L. Scrivener, Effects of uniaxial stress on alkali-silica reaction induced expansion of concrete, Cem. Concr. Res. 42 (2012) $567-576$.

[10] B.P. Gautam, D.K. Panesar, A new method of applying long-term multiaxial stresses in concrete specimens undergoing ASR, and their triaxial expansions, Mater. Struct. 49 (2016) 3495-3508.

[11] AENOR, Cement-Part 1: Composition, specifications and conformity criteria for common cements UNE-EN 197-1. AENOR, Madrid, 2011.

[12] E. Brühwiler, F. Wittmann, The wedge splitting test, a new method of performing stable fracture mechanics tests, Eng. Fract. Mech. 35 (1990) $117-125$.

[13] J. Liaudat, D. Garolera, A. Martínez, I. Carol, M.R. Lakshmikantha, J. Alvarellos, Numerical modelling of the Wedge Splitting Test in rock specimens, using fracture-based zero-thickness interface elements, in: E. Oñate, D.R.J. Owen, D. Peric, M. Chiumeti (Eds.), XIII International Conference on Computational Plasticity - Fundamentals and Applications. CIMNE, Barcelona, 2015, pp 974-981.

[14] V.E. Saouma, L. Perotti, Constitutive Model for Alkali-Aggregate Reactions, ACI Mater. J. 103 (2006) 194-202. 